Article

\title{
Friction and Wear of Self-Lubricating Materials for Hydropower Applications under Different Lubricating Conditions
}

\author{
Kim Berglund * and Yijun Shi \\ Division of Machine Elements, Luleå University of Technology, Luleå 97187, Sweden; yijun.shi@ltu.se \\ * Correspondence: kim.berglund@ltu.se; Tel.: +46-920-493051 \\ Academic Editor: James E. Krzanowski \\ Received: 12 April 2017; Accepted: 11 July 2017; Published: 15 July 2017
}

\begin{abstract}
Self-lubricating bearings in hydropower applications are often lubricated with water under boundary lubricating conditions. Polyhydric alcohols replacing water have shown the potential to reduce both friction and wear. The objective of this work is, therefore, to evaluate the effect of a polyhydric alcohol-based environmentally-acceptable lubricant (EAL) on the friction and wear of self-lubricating materials for conformal contacts under boundary lubricating conditions. The lubricating properties of four commercially-available self-lubricating bearing materials were investigated under three different lubricating conditions: dry, water and a new polyhydric alcohol-based EAL. Bearing materials include one metallic composite and three polymer composites. A reciprocating motion test rig was used to evaluate the wear and friction properties. Surface analysis was performed by scanning electron microscopy (SEM), energy-dispersive X-ray spectroscopy (EDS), and optical profilometry. Results show that the wear rate for the polymer composites is increased when water is present compared to dry operating conditions. The new polyhydric alcohol-based EAL substantially improves both friction and anti-wear performance of all four self-lubricating bearing materials compared to both dry and water conditions. Surface analysis indicates that the material transfer to the counter-surface is limited when the polyhydric alcohol-based EAL is used.
\end{abstract}

Keywords: friction; wear; self-lubricating; EAL; hydropower

\section{Introduction}

Self-lubricating bearing materials are used extensively from hydropower to marine and offshore applications. In hydropower, there is a striving to replace the use of conventional grease and oil lubricated bearings to eliminate the risk of lubricant leakage into downstream water [1]. Thus, the use of self-lubricating bearing materials in hydropower turbines has increased in recent years. Typically, the expected service life of a self-lubricating bearing material in a hydropower turbine is substantial, i.e., around 40 years. During this time, the increase in bearing clearance due to wear should not exceed a specific threshold value specified in the turbine design. Further, the friction level must also be steady throughout the service life. Otherwise, turbine operation may be adversely affected.

Self-lubricating bearing materials for hydropower applications are often used in aqueous environments, e.g., the trunnion and guide vane bearings in a hydropower turbine. The water is a sealed closed system, typically with some additive to reduce the risk of corrosion. In the case of leakage, there will be little to no harm to the environment.

Transfer film formation has been shown to be an important mechanism governing friction and wear of many different types of self-lubricating composites [2]. However, previous studies of self-lubricating polymers have shown that the presence of water may adversely affect the wear behaviour [3-5]. For some polymers, e.g., PTFE, the tribological properties, such as friction and wear, 
are governed by the formation of a transfer layer on the counter-surface and water has been shown to interfere with this type of transfer layer formation [6-8]. Water has also been shown to diffuse into the polymer material, which causes the reduction of mechanical properties of the polymer resulting in decreased wear resistance of the polymer. To improve the lubricating properties of water, different types of additives have been investigated. Wasilewski and Sulek showed that alkyl polyglucosides as water additives could improve friction and anti-wear properties, as well as resistance to seizure [9]. Alkyl sulphates have also been shown to successfully modify the tribological properties of water under boundary lubricating conditions [10]. Ratoi and Spikes [11] investigated a range of different surfactant-water solutions in rolling contacts and showed that surfactants could adsorb on the solid surfaces to form a boundary film in the range of 2 to $4 \mathrm{~nm}$ at low sliding speeds. The efficiency of boundary film formation was dependent on both surfactant type and concentration.

Another approach to improve the lubricating properties of water is to change the type of base fluid. Several researchers have shown that superlubricity, i.e., friction coefficient levels below 0.01 , can be reached by using polyhydric alcohols as lubricant [12-14]. Polyhydric alcohols have shown promising performance in all lubrication regimes and under a wide range of operating conditions. Most investigations on polyhydric alcohols, however, have been performed under high pressure and for non-conformal contacts. Very little research has been performed when it comes to the lower pressures of conformal contacts which are commonly found in journal bearings or bushings. Most investigations have also only focused on steel-steel or steel-bronze contacts. Very little is known about how a polyhydric alcohol based lubricant would affect the friction and wear of conventional self-lubricating materials.

The objective of this work is therefore to evaluate the effect of a polyhydric alcohol-based environmentally acceptable lubricant (EAL) on friction and anti-wear properties of self-lubricating materials for conformal contacts under boundary lubricating conditions.

\section{Results}

In this study, four different bearing materials were investigated: sintered bronze (deva.bm), two thermoset composite materials (Orkot TXMM, deva.tex) and one thermoplastic polymer material (Thordon Thorplas). Three different lubricating conditions were used: dry, water, and lubricated by the polyhydric alcohol-based EAL SustainaLube. For more information about the test setup, see Section 4.

\subsection{Friction and Wear}

The wear rates for the tested materials can be seen in Figures 1, 3, 5, and 7 and the friction coefficient values during the tests can be seen in Figures 2, 4, 6, and 8 .

When the deva.bm friction material is used in water, the test is stopped after around one hour of testing due to a rapid increase in the friction coefficient and wear rate (see Figures 1 and 2). The deva.bm bearing material shows steady friction coefficient values of about $0.2 \pm 0.05$ during the test under dry operating conditions (Figure 2). The SustainaLube lubricant significantly improves the friction and anti-wear properties.

The mean wear coefficient of the deva.tex bearing material is increased significantly under water lubrication compared to dry operating conditions (Figure 3). It can also be observed that wear could not be detected during the time period of the tests when the SustainaLube lubricant is used in combination with the deva.tex bearing material. Friction coefficient levels for the deva.tex bearing materials under dry operating conditions are in the region of 0.15 . Lower friction levels are observed when water is used (Figure 4). With SustainaLube, the mean friction coefficient is decreased to about 0.01 at the end of the test. 


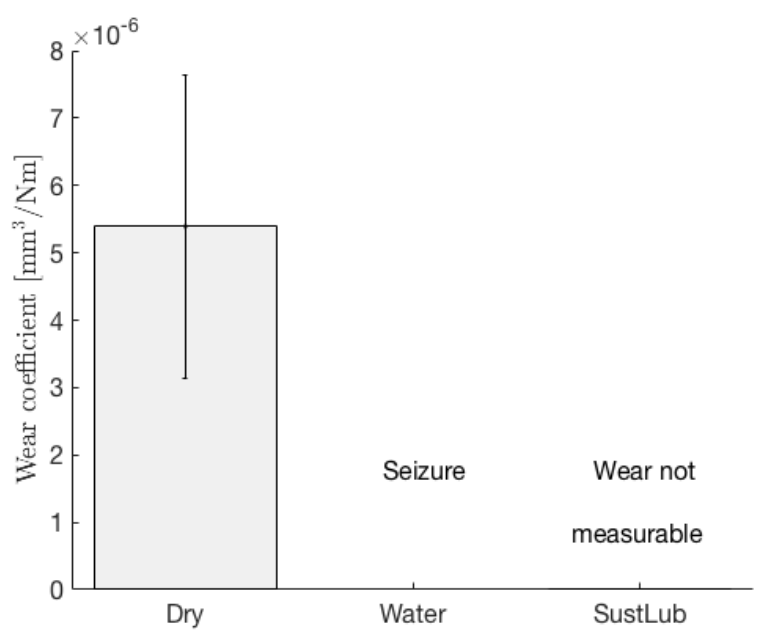

Figure 1. Wear rate of the deva.bm bearing material.

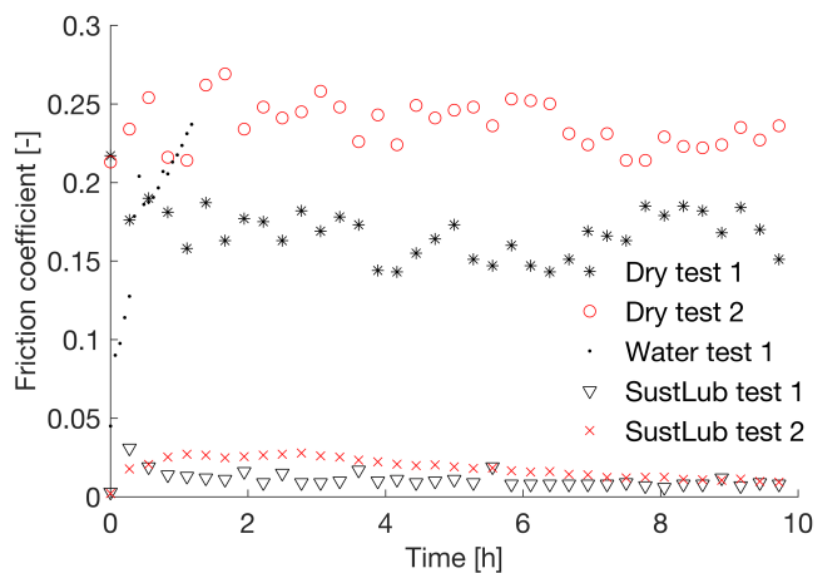

Figure 2. Friction coefficient during test for the deva.bm bearing material.

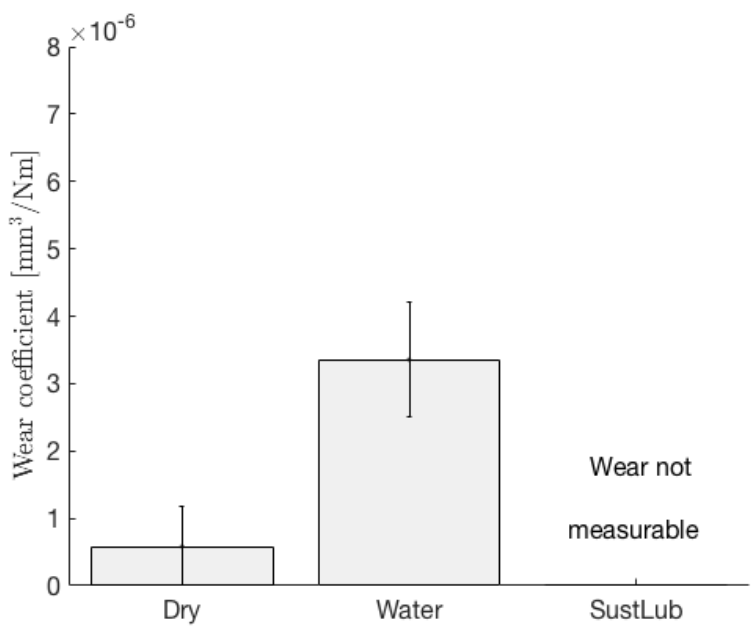

Figure 3. Wear rate of the deva.tex bearing material.

The wear rate and friction coefficient of the Thordon bearing material are increased under water lubrication compared to dry operating conditions (see Figures 5 and 6). SustainaLube together with 
Thordon bearing material shows low friction levels at the end of test, as well as low wear compared to dry and water lubricated conditions.

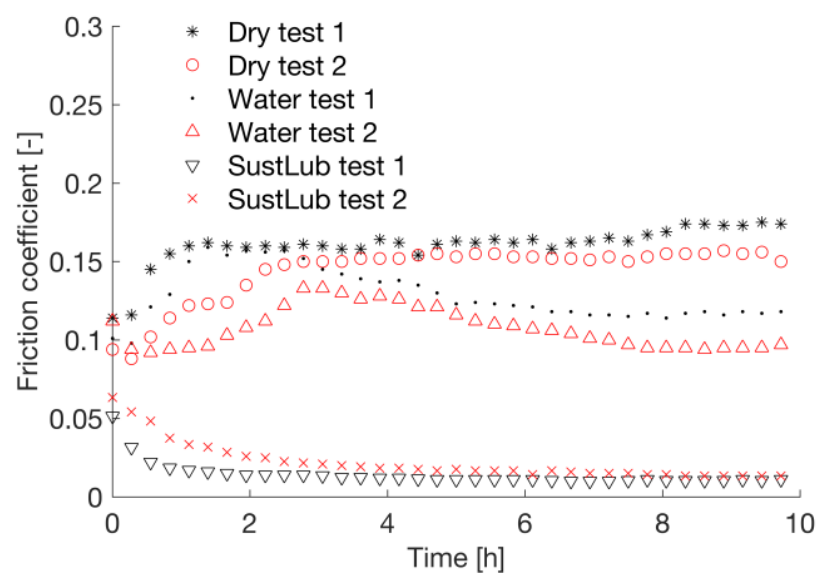

Figure 4. Friction coefficient during test for the deva.tex bearing material.

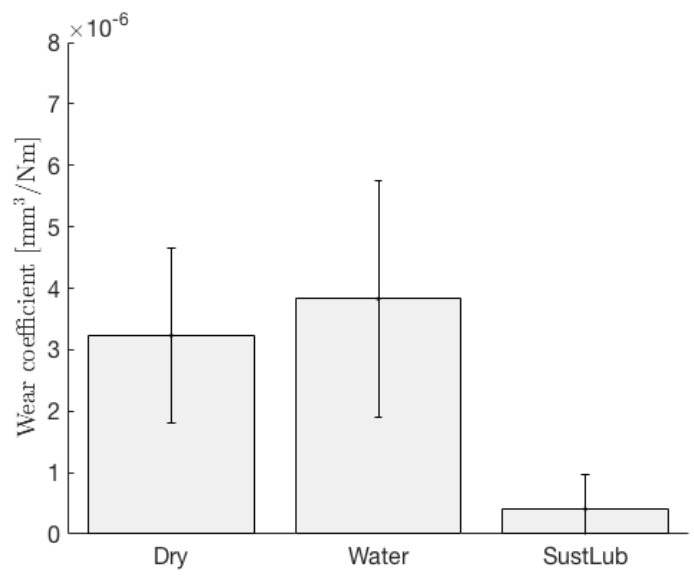

Figure 5. Wear rate of the Thordon bearing material.

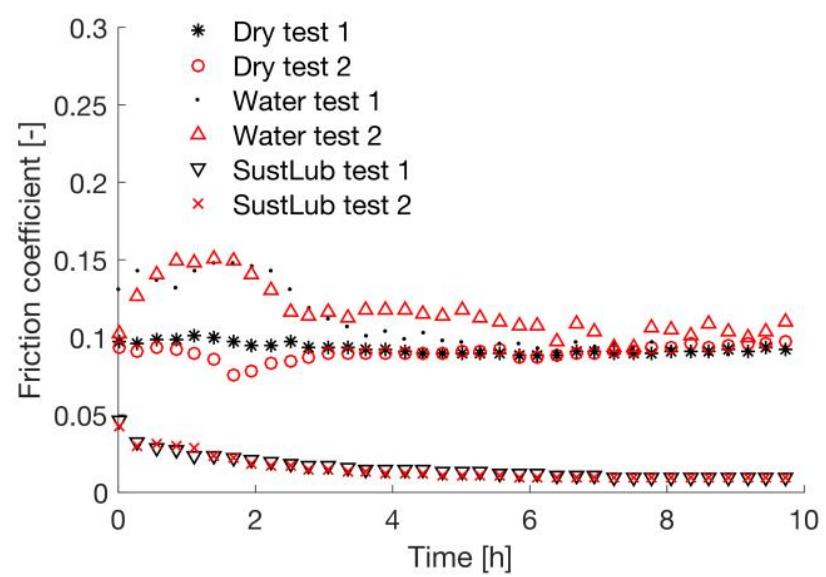

Figure 6. Friction coefficient during test for the Thordon bearing material.

In terms of wear, a similar trend as for other bearing materials is found for the Orkot TXMM where the highest wear is found for water lubricated conditions and the lowest wear levels are found 
when SustainaLube is used (Figure 7). However, the friction coefficient is the highest among the dry tests (Figure 8).

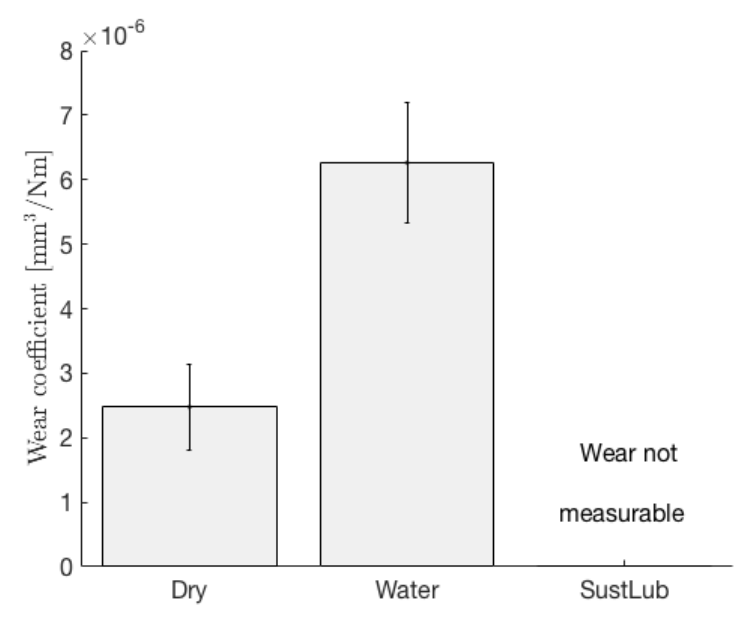

Figure 7. Wear rate of the Orkot bearing material.

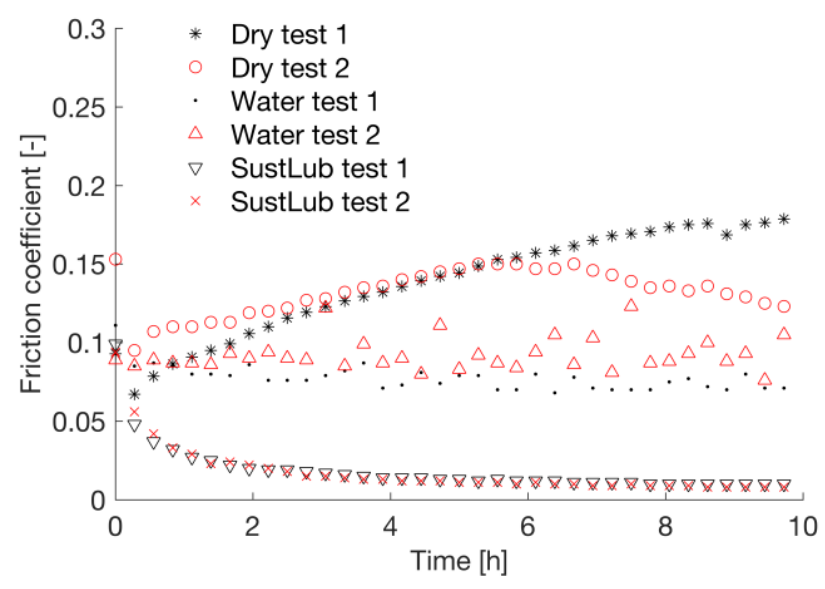

Figure 8. Friction coefficient during test for the Orkot bearing material.

Based on the results from the tribological experiments, the thermoplastic Thordon Thorplas and bronze-based deva.bm were selected for further surface analysis to investigate the origin of the very different friction and wear response of water compared to the polyhydric alcohol-based SustainaLube.

\subsection{Surface Roughness by Optical Profilometry}

When Thordon Thorplas is used in combination with water, material transfer to the corresponding stainless steel counter-surface is found (Figure 9). The left part of the image represents one of the outer ends of the wear track which is higher than the unworn right part of the image. When SustainaLube is used instead of water, less transfer of material occurs and smooth, larger areas are formed (Figure 10).

A severe wear situation with deep grooves in the stainless steel counter-surface is found after only $0.5 \mathrm{~h}$ of testing when deva.bm is used together with water (Figure 11). The test had to be aborted after this time due to high friction. A smoother stainless steel counter-surface is observed after $0.5 \mathrm{~h}$ of testing when SustainaLube is used together with the deva.bm material, see Figure 12. After $8 \mathrm{~h}$ of testing, the SustainaLube/deva.bm combination gives a large, smooth area formed on the stainless steel counter-surface (Figure 13). 


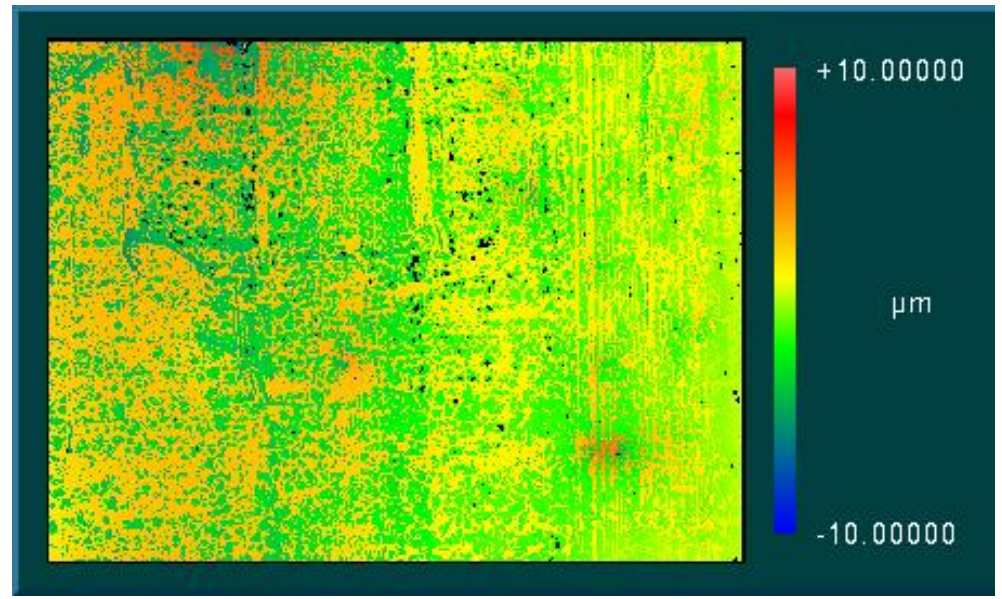

Figure 9. Surface topography of the stainless steel counter-surface after an 8-h test with water and Thordon Thorplas. Magnification: $10 \times$.

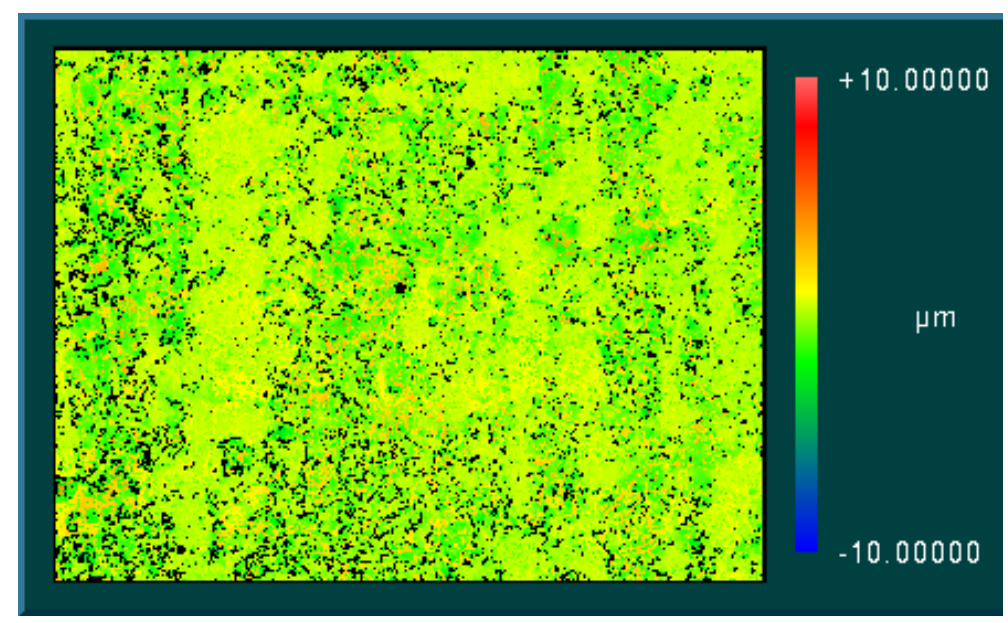

Figure 10. Surface topography of the stainless steel counter-surface after an 8-h test with SustainaLube and Thordon Thorplas. Magnification: $10 \times$.

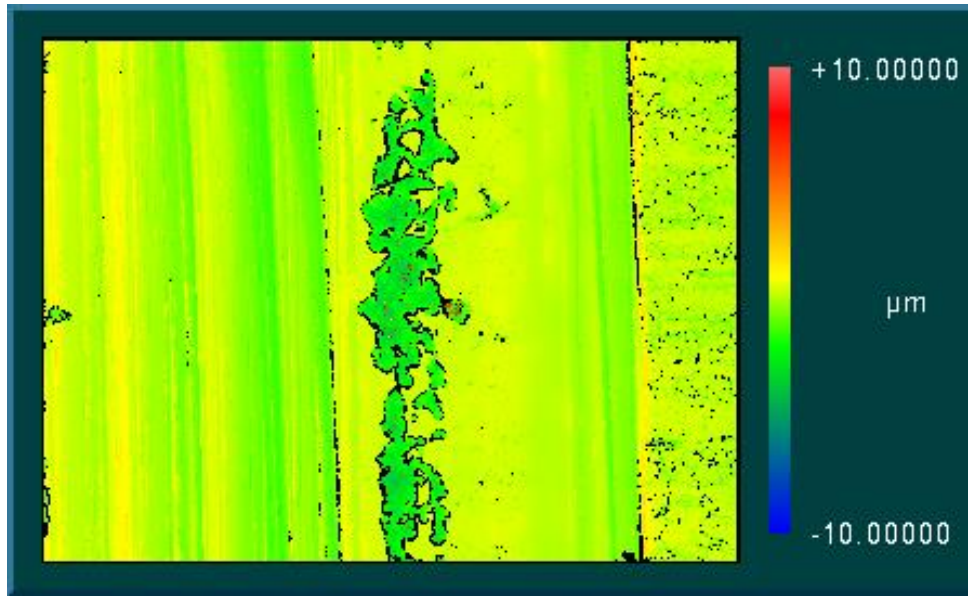

Figure 11. Surface topography of the stainless steel counter-surface after a 0.5 -h test with water and deva.bm. Magnification: $10 \times$. 


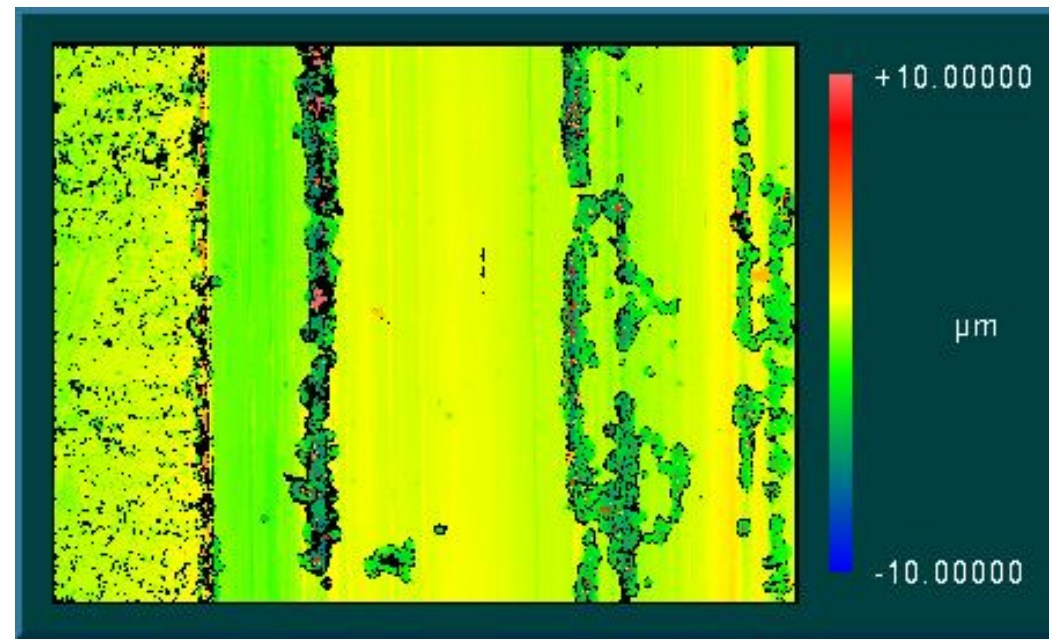

Figure 12. Surface topography of the stainless steel counter-surface after a 0.5 -h test with SustainaLube and deva.bm. Magnification: $10 \times$.

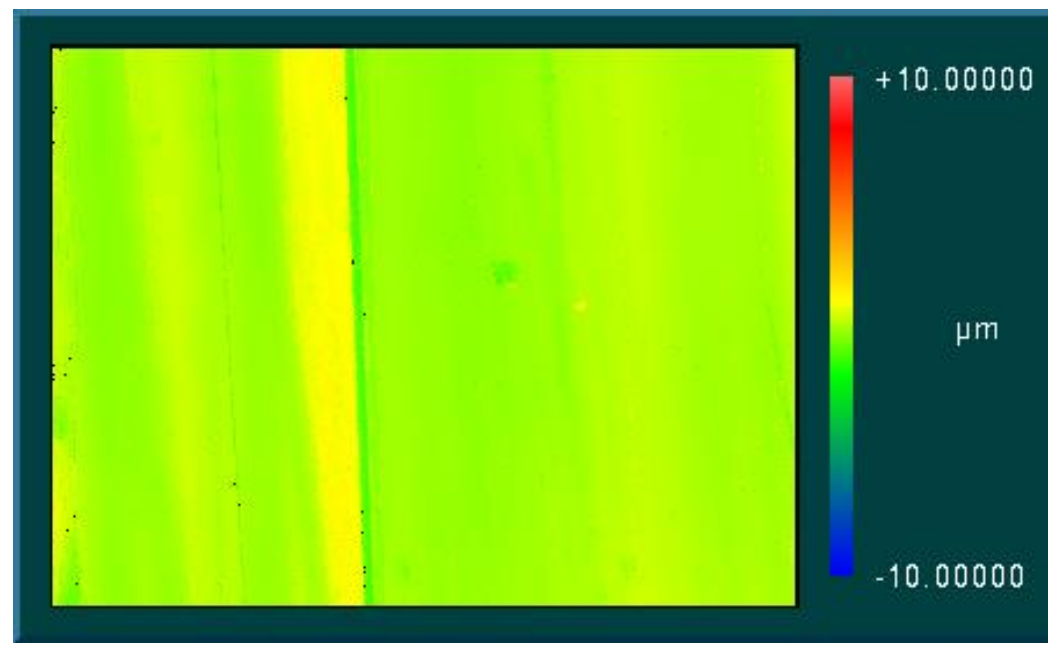

Figure 13. Surface topography of stainless steel counter-surface after an 8-h test with SustainaLube and deva.bm. Magnification: $10 \times$.

\subsection{Surface Analysis by Scanning Electron Microscopy (SEM) and Energy Dispersive X-ray Spectroscopy (EDS)}

When Thordon Thorplas is lubricated with water, dark to black patches are found on the stainless steel counter-surface (Figure 14). EDS analysis is performed at selected locations marked in Figure 14. The corresponding elemental content is listed in Table 1. A high content of carbon together with the surface topography measurement of Figure 9 indicate that these patches correspond to material transfer of the polymer to the counter-surface. These patches are mainly visible at the ends of the wear track and may be an indication of the high wear situation. Since these patches are separated from each other, they cannot provide effective protection for the material.

When SustainaLube and Thordon Thorplas is used, less evidence of material transfer to the counter-surface can be found (Figure 15). Areas 5 and 6 are right outside one of the end positions of the wear track and, thus, represent unworn material. Some transferred material can be seen on the counter-surface at the end of the wear track. EDS analysis shows that there is less zinc inside the wear track compared to the unworn surface (Table 2). Normally, the steel surface is coated with a thin layer of zinc. 


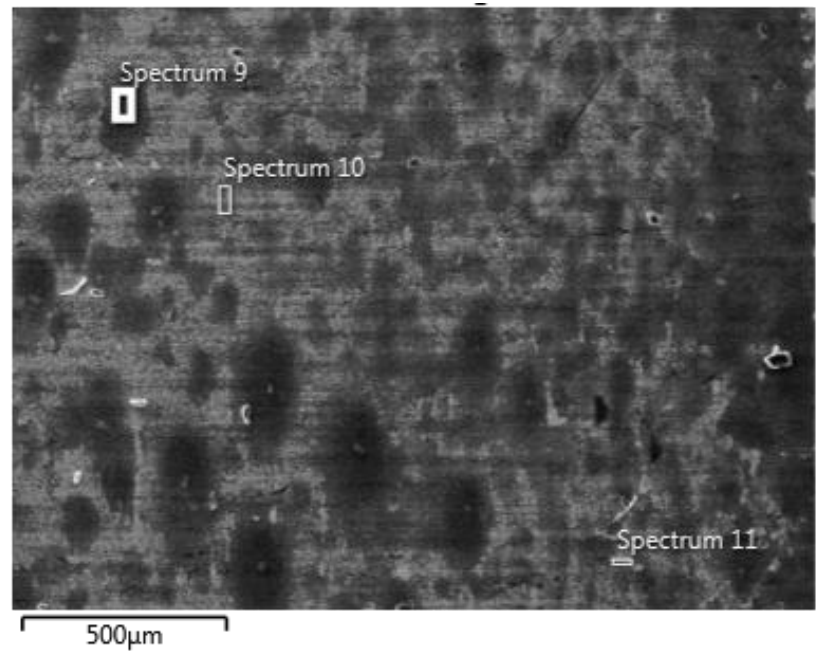

Figure 14. SEM micrograph of stainless steel counter-surface after an 8 -h test with water and Thordon Thorplas.

Table 1. EDS spectra of the stainless steel counter-surface after an 8-h test with water and Thordon Thorplas.

\begin{tabular}{|c|c|c|c|c|c|c|c|c|}
\hline \multicolumn{9}{|c|}{ Spectrum Number } \\
\hline \multicolumn{3}{|c|}{9} & \multicolumn{3}{|c|}{10} & \multicolumn{3}{|c|}{11} \\
\hline Element & wt \% & wt $\% \sigma$ & Elem. & wt \% & wt $\% \sigma$ & Elem. & wt \% & wt $\% \sigma$ \\
\hline $\mathrm{C}$ & 46.68 & 0.26 & $\mathrm{C}$ & 29.63 & 0.35 & $\mathrm{C}$ & 24.11 & 0.38 \\
\hline $\mathrm{O}$ & 12.54 & 0.18 & $\mathrm{O}$ & 6.36 & 0.17 & $\mathrm{O}$ & 6.09 & 0.17 \\
\hline $\mathrm{F}$ & 1.35 & 0.10 & $\mathrm{Al}$ & 0.09 & 0.03 & $\mathrm{Al}$ & 0.02 & 0.04 \\
\hline $\mathrm{Al}$ & 0.03 & 0.02 & $\mathrm{Si}$ & 0.26 & 0.03 & $\mathrm{Si}$ & 0.32 & 0.03 \\
\hline $\mathrm{Si}$ & 0.19 & 0.02 & $\mathrm{Ti}$ & 0.00 & 0.00 & $\mathrm{Ti}$ & 0.00 & 0.00 \\
\hline $\mathrm{Ti}$ & 0.00 & 0.00 & V & 0.11 & 0.03 & $\mathrm{~V}$ & 0.09 & 0.03 \\
\hline $\mathrm{V}$ & 0.02 & 0.02 & $\mathrm{Cr}$ & 12.76 & 0.11 & $\mathrm{Cr}$ & 13.74 & 0.12 \\
\hline $\mathrm{Cr}$ & 7.84 & 0.07 & $\mathrm{Fe}$ & 45.87 & 0.27 & $\mathrm{Fe}$ & 50.06 & 0.29 \\
\hline $\mathrm{Fe}$ & 28.16 & 0.17 & $\mathrm{Ni}$ & 4.93 & 0.09 & $\mathrm{Ni}$ & 5.32 & 0.10 \\
\hline $\mathrm{Ni}$ & 3.01 & 0.06 & Total & 100.00 & & $\mathrm{Zn}$ & 0.25 & 0.07 \\
\hline $\mathrm{Zn}$ & 0.18 & 0.05 & & & & Total & 100.00 & \\
\hline
\end{tabular}

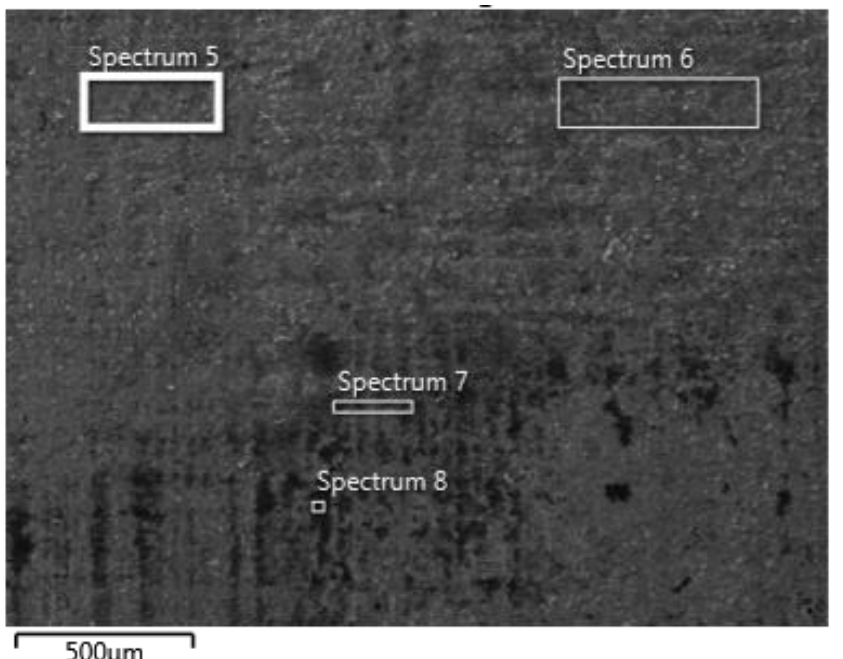

Figure 15. SEM micrograph of the stainless steel counter-surface after an 8-h test with SustainaLube and Thordon Thorplas. 
Table 2. EDS spectra of stainless steel counter-surface after an 8-h test with SustainaLube and Thordon Thorplas.

\begin{tabular}{|c|c|c|c|c|c|c|c|c|c|c|c|}
\hline \multicolumn{12}{|c|}{ Spectrum Number } \\
\hline \multicolumn{3}{|c|}{5} & \multicolumn{3}{|c|}{6} & \multicolumn{3}{|c|}{7} & \multicolumn{3}{|c|}{8} \\
\hline Element & wt \% & wt $\% \sigma$ & Elem. & wt $\%$ & wt $\% \sigma$ & Elem. & wt $\%$ & wt $\% \sigma$ & Elem. & wt $\%$ & wt $\% \sigma$ \\
\hline $\mathrm{C}$ & 12.40 & 0.37 & $\mathrm{C}$ & 15.76 & 0.38 & $\mathrm{C}$ & 22.88 & 0.36 & $\mathrm{C}$ & 37.83 & 0.29 \\
\hline $\mathrm{O}$ & 14.59 & 0.18 & $\mathrm{O}$ & 10.54 & 0.18 & $\mathrm{O}$ & 7.64 & 0.17 & $\mathrm{O}$ & 10.16 & 0.16 \\
\hline $\mathrm{Na}$ & 4.85 & 0.25 & $\mathrm{Na}$ & 3.40 & 0.21 & $\mathrm{Na}$ & 1.22 & 0.14 & $\mathrm{Al}$ & 0.01 & 0.02 \\
\hline $\mathrm{Al}$ & 0.01 & 0.04 & $\mathrm{Al}$ & 0.01 & 0.04 & $\mathrm{Al}$ & 0.04 & 0.03 & $\mathrm{Si}$ & 0.22 & 0.02 \\
\hline $\mathrm{Si}$ & 0.23 & 0.04 & $\mathrm{Si}$ & 0.29 & 0.03 & $\mathrm{Si}$ & 0.28 & 0.03 & $\mathrm{Ti}$ & 0.00 & 0.00 \\
\hline $\mathrm{Ti}$ & 0.00 & 0.00 & $\mathrm{Ti}$ & 0.00 & 0.00 & $\mathrm{Ti}$ & 0.00 & 0.00 & $\mathrm{~V}$ & 0.08 & 0.02 \\
\hline $\mathrm{V}$ & 0.08 & 0.03 & $\mathrm{~V}$ & 0.07 & 0.03 & $\mathrm{~V}$ & 0.09 & 0.03 & $\mathrm{Cr}$ & 10.38 & 0.08 \\
\hline $\mathrm{Cr}$ & 11.32 & 0.10 & $\mathrm{Cr}$ & 12.56 & 0.11 & $\mathrm{Cr}$ & 13.03 & 0.11 & $\mathrm{Fe}$ & 37.10 & 0.20 \\
\hline $\mathrm{Fe}$ & 40.32 & 0.26 & $\mathrm{Fe}$ & 44.86 & 0.27 & $\mathrm{Fe}$ & 47.39 & 0.27 & $\mathrm{Ni}$ & 3.91 & 0.07 \\
\hline $\mathrm{Ni}$ & 4.36 & 0.09 & $\mathrm{Ni}$ & 4.79 & 0.09 & $\mathrm{Ni}$ & 5.08 & 0.09 & $\mathrm{Zn}$ & 0.30 & 0.05 \\
\hline $\mathrm{Zn}$ & 11.83 & 0.16 & $\mathrm{Zn}$ & 7.72 & 0.13 & $\mathrm{Zn}$ & 2.33 & 0.09 & Total & 100.00 & \\
\hline Total & 100.00 & & Total & 100.00 & & Total & 100.00 & & & & \\
\hline
\end{tabular}

When the deva.bm material and water is used, grooves can be observed in the stainless steel counter-surface indicating a severe wear situation (Figure 16). The SEM micrograph in Figure 16 is taken after a half an hour test which is stopped due to the high friction increase observed in Figure 2. Copper from the deva.bm material can be found in the wear track (Table 3).

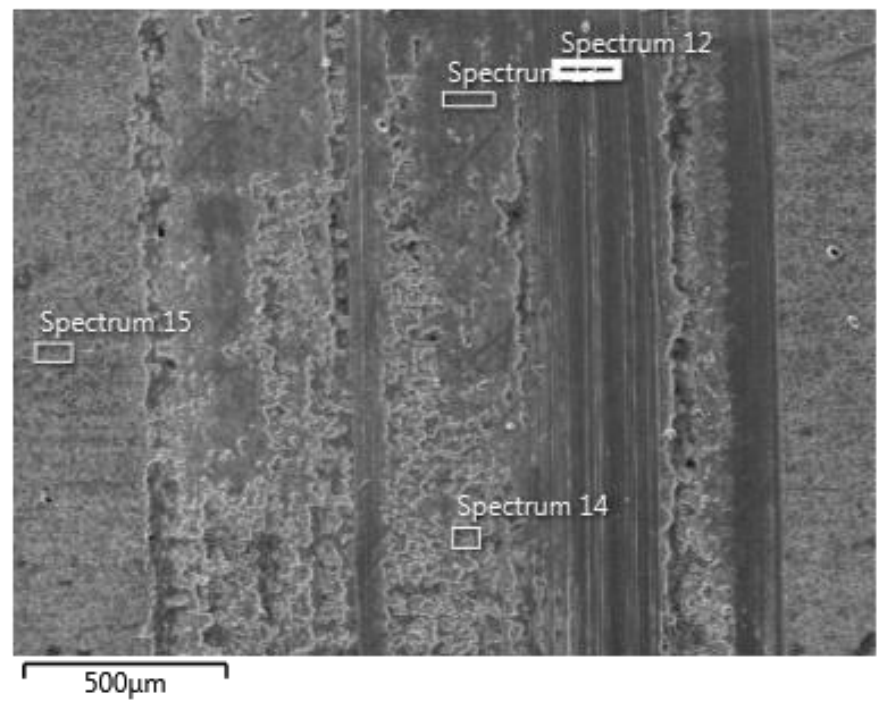

Figure 16. SEM micrograph of the stainless steel counter-surface after a 0.5-h test with water and deva.bm.

Table 3. EDS spectra of the stainless steel counter-surface after a 0.5-h test with water and deva.bm.

\begin{tabular}{|c|c|c|c|c|c|c|c|c|c|c|c|}
\hline \multicolumn{12}{|c|}{ Spectrum Number } \\
\hline \multicolumn{3}{|c|}{12} & \multicolumn{3}{|c|}{13} & \multicolumn{3}{|c|}{14} & \multicolumn{3}{|c|}{15} \\
\hline Elem. & wt $\%$ & wt $\% \sigma$ & Elem. & wt $\%$ & wt $\% \sigma$ & Elem. & wt $\%$ & wt $\% \sigma$ & Elem. & wt $\%$ & wt $\%$ o \\
\hline $\mathrm{C}$ & 6.39 & 0.38 & $\mathrm{C}$ & 8.44 & 0.39 & $\mathrm{C}$ & 11.38 & 0.43 & $\mathrm{C}$ & 11.05 & 0.41 \\
\hline $\mathrm{O}$ & 0.82 & 0.15 & $\mathrm{O}$ & 1.13 & 0.15 & $\mathrm{O}$ & 11.41 & 0.20 & $\mathrm{O}$ & 1.47 & 0.15 \\
\hline $\mathrm{Al}$ & 0.00 & 0.00 & $\mathrm{Al}$ & 0.04 & 0.05 & $\mathrm{Na}$ & 4.09 & 0.29 & $\mathrm{Al}$ & 0.07 & 0.05 \\
\hline $\mathrm{Si}$ & 0.48 & 0.05 & $\mathrm{Si}$ & 0.37 & 0.05 & $\mathrm{Al}$ & 0.00 & 0.00 & $\mathrm{Si}$ & 0.39 & 0.05 \\
\hline $\mathrm{Ti}$ & 0.00 & 0.00 & $\mathrm{Ti}$ & 0.00 & 0.00 & $\mathrm{Si}$ & 0.31 & 0.04 & $\mathrm{Ti}$ & 0.01 & 0.04 \\
\hline $\mathrm{V}$ & 0.13 & 0.04 & $\mathrm{~V}$ & 0.13 & 0.04 & $\mathrm{Ti}$ & 0.03 & 0.03 & $\mathrm{~V}$ & 0.07 & 0.04 \\
\hline $\mathrm{Cr}$ & 18.08 & 0.14 & $\mathrm{Cr}$ & 16.64 & 0.14 & $\mathrm{~V}$ & 0.10 & 0.04 & $\mathrm{Cr}$ & 17.10 & 0.14 \\
\hline $\mathrm{Fe}$ & 66.56 & 0.33 & $\mathrm{Fe}$ & 61.85 & 0.33 & $\mathrm{Cr}$ & 11.30 & 0.12 & $\mathrm{Fe}$ & 62.61 & 0.35 \\
\hline $\mathrm{Ni}$ & 7.54 & 0.13 & $\mathrm{Ni}$ & 7.39 & 0.13 & $\mathrm{Fe}$ & 39.98 & 0.29 & $\mathrm{Ni}$ & 6.93 & 0.13 \\
\hline \multirow[t]{4}{*}{ Total: } & 100.00 & & $\mathrm{Cu}$ & 4.01 & 0.12 & $\mathrm{Ni}$ & 4.46 & 0.10 & $\mathrm{Zn}$ & 0.29 & 0.09 \\
\hline & & & Total & 100.00 & & $\mathrm{Cu}$ & 2.95 & 0.10 & Total & 100.00 & \\
\hline & & & & & & $\mathrm{Zn}$ & 13.99 & 0.19 & & & \\
\hline & & & & & & Total & 100.00 & & & & \\
\hline
\end{tabular}


When deva.bm is used together with SustainaLube, an initial wear of the top layer can be observed (Figure 17). Both zinc and copper are found on large parts of the surface (Table 4).

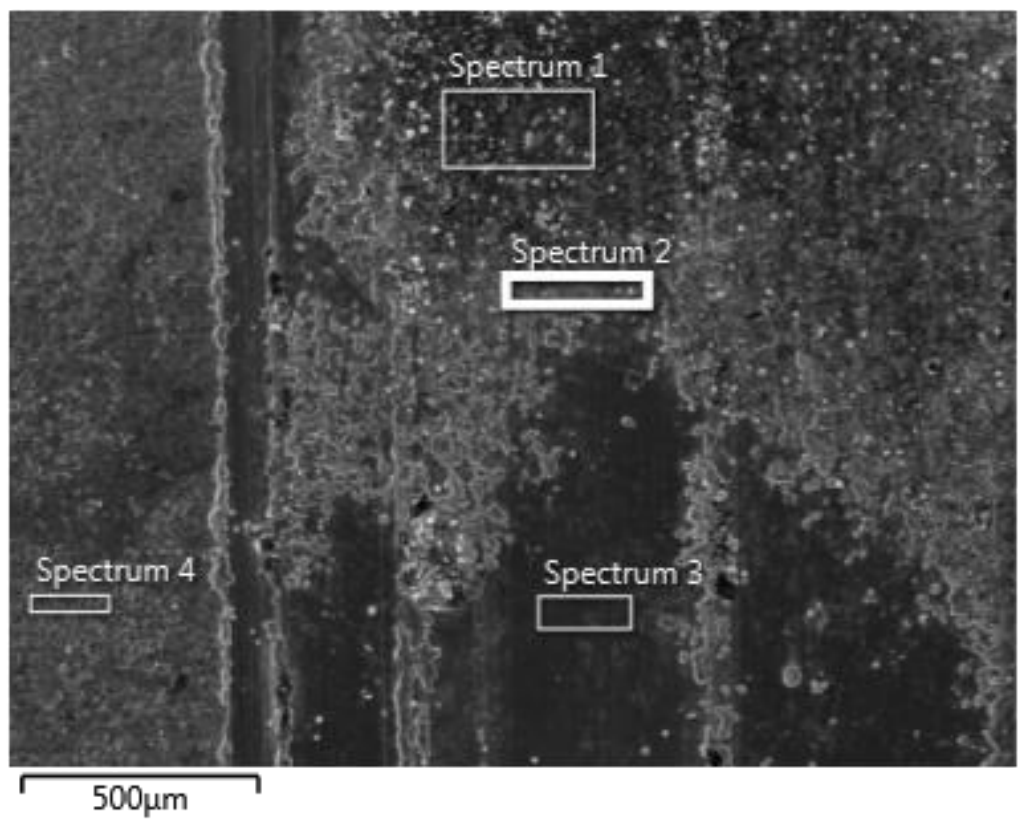

Figure 17. SEM micrograph of the stainless steel counter-surface after a 0.5 -h test with SustainaLube and deva.bm.

Table 4. EDS spectra of the stainless steel counter-surface after a 0.5-h test with SustainaLube and deva.bm.

\begin{tabular}{|c|c|c|c|c|c|c|c|c|c|c|c|}
\hline \multicolumn{12}{|c|}{ Spectrum Number } \\
\hline \multicolumn{3}{|c|}{1} & \multicolumn{3}{|c|}{2} & \multicolumn{3}{|c|}{3} & \multicolumn{3}{|c|}{4} \\
\hline Elem. & wt \% & wt $\% \sigma$ & Elem. & wt $\%$ & wt $\% \sigma$ & Elem. & wt $\%$ & wt $\% \sigma$ & Elem. & wt $\%$ & wt $\% 0$ \\
\hline C & 12.60 & 0.37 & $\mathrm{C}$ & 12.48 & 0.38 & C & 6.34 & 0.30 & C & 10.69 & 0.35 \\
\hline $\mathrm{O}$ & 22.33 & 0.22 & $\mathrm{O}$ & 22.74 & 0.23 & $\mathrm{O}$ & 0.98 & 0.13 & $\mathrm{O}$ & 9.84 & 0.17 \\
\hline $\mathrm{Na}$ & 5.61 & 0.31 & $\mathrm{Na}$ & 6.21 & 0.31 & $\mathrm{Al}$ & 0.24 & 0.05 & $\mathrm{Na}$ & 3.47 & 0.23 \\
\hline $\mathrm{Al}$ & 0.12 & 0.04 & $\mathrm{Al}$ & 0.20 & 0.04 & $\mathrm{Si}$ & 0.48 & 0.04 & $\mathrm{Al}$ & 0.11 & 0.04 \\
\hline $\mathrm{Ti}$ & 0.00 & 0.03 & $\mathrm{Ti}$ & 0.01 & 0.03 & $\mathrm{Ti}$ & 0.00 & 0.03 & $\mathrm{Si}$ & 0.36 & 0.04 \\
\hline $\mathrm{V}$ & 0.03 & 0.03 & $\mathrm{~V}$ & 0.05 & 0.03 & $\mathrm{~V}$ & 0.13 & 0.04 & $\mathrm{Ti}$ & 0.00 & 0.00 \\
\hline $\mathrm{Cr}$ & 6.97 & 0.08 & $\mathrm{Cr}$ & 6.32 & 0.08 & $\mathrm{Cr}$ & 17.91 & 0.12 & $\mathrm{~V}$ & 0.07 & 0.03 \\
\hline $\mathrm{Fe}$ & 22.84 & 0.18 & $\mathrm{Fe}$ & 20.95 & 0.17 & $\mathrm{Fe}$ & 65.71 & 0.27 & $\mathrm{Cr}$ & 13.14 & 0.11 \\
\hline $\mathrm{Ni}$ & 2.52 & 0.07 & $\mathrm{Ni}$ & 2.17 & 0.07 & $\mathrm{Ni}$ & 7.40 & 0.11 & $\mathrm{Fe}$ & 47.45 & 0.27 \\
\hline $\mathrm{Cu}$ & 1.45 & 0.07 & $\mathrm{Cu}$ & 0.99 & 0.07 & $\mathrm{Cu}$ & 0.80 & 0.08 & $\mathrm{Ni}$ & 5.16 & 0.10 \\
\hline $\mathrm{Zn}$ & 25.54 & 0.22 & $\mathrm{Zn}$ & 27.89 & 0.23 & Total & 100.00 & & $\mathrm{Zn}$ & 9.71 & 0.14 \\
\hline Total & 100.00 & & Total & 100.00 & & & & & Total & 100.00 & \\
\hline
\end{tabular}

After the 8-h test, the stainless steel counter-surface appears very smooth for the SustainaLube and deva.bm combination (Figure 18). The wear surface is rich in both carbon and oxygen and no traces of copper and low levels of zinc can be found (Table 5). 


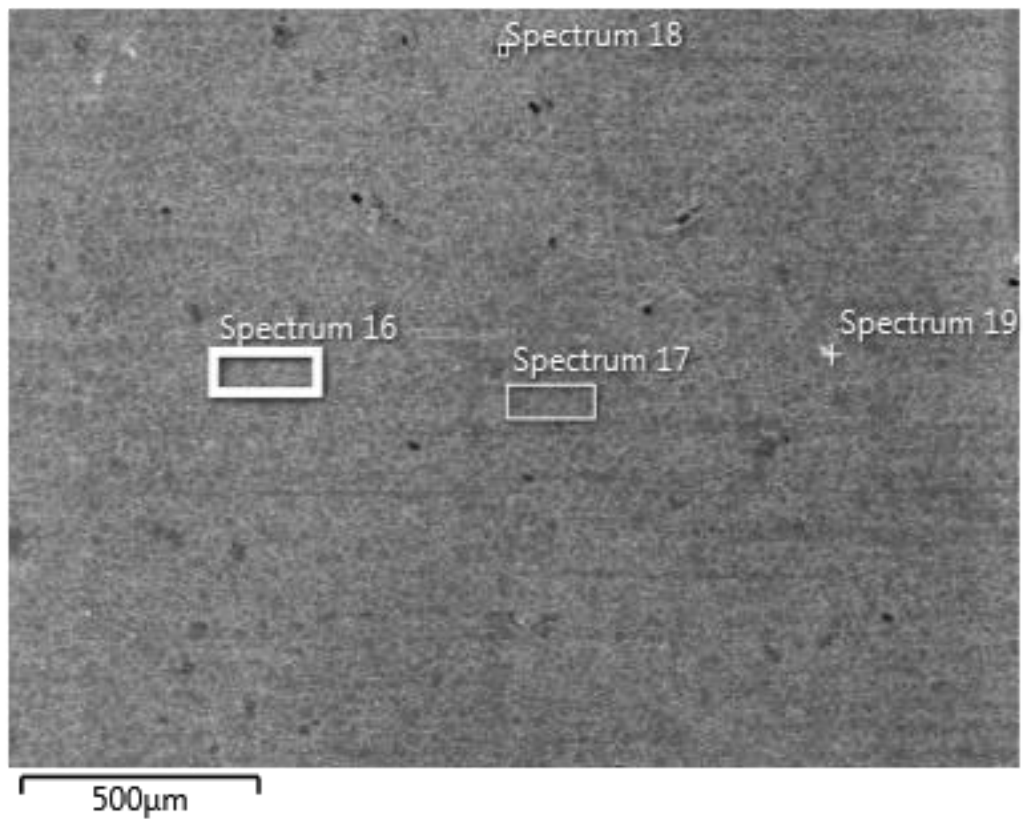

Figure 18. SEM micrograph of the stainless steel counter-surface after an 8-h test with SustainaLube and deva.bm.

Table 5. EDS spectra of the stainless steel counter-surface after an 8-h test with SustainaLube and deva.bm.

\begin{tabular}{|c|c|c|c|c|c|c|c|c|c|c|c|}
\hline \multicolumn{12}{|c|}{ Spectrum Number } \\
\hline \multicolumn{3}{|c|}{16} & \multicolumn{3}{|c|}{17} & \multicolumn{3}{|c|}{18} & \multicolumn{3}{|c|}{19} \\
\hline Elem. & wt $\%$ & wt $\% \sigma$ & Elem. & wt $\%$ & wt $\% \sigma$ & Elem. & wt $\%$ & wt $\% \sigma$ & Elem. & wt $\%$ & wt $\% \sigma$ \\
\hline C & 11.45 & 0.41 & C & 9.01 & 0.40 & C & 48.66 & 0.38 & C & 40.83 & 0.32 \\
\hline $\mathrm{O}$ & 1.82 & 0.16 & $\mathrm{O}$ & 1.42 & 0.15 & $\mathrm{O}$ & 13.60 & 0.28 & $\mathrm{O}$ & 10.51 & 0.20 \\
\hline $\mathrm{Al}$ & 0.16 & 0.05 & $\mathrm{Al}$ & 0.16 & 0.05 & $\mathrm{Na}$ & 1.07 & 0.11 & $\mathrm{Al}$ & 0.07 & 0.03 \\
\hline $\mathrm{Si}$ & 0.47 & 0.05 & $\mathrm{Si}$ & 0.36 & 0.05 & $\mathrm{Al}$ & 0.08 & 0.03 & $\mathrm{Si}$ & 0.22 & 0.02 \\
\hline $\mathrm{Ti}$ & 0.00 & 0.00 & $\mathrm{Ti}$ & 0.03 & 0.04 & $\mathrm{Si}$ & 0.28 & 0.03 & $\mathrm{Ti}$ & 0.02 & 0.02 \\
\hline V & 0.12 & 0.04 & V & 0.05 & 0.04 & S & 0.15 & 0.02 & V & 0.05 & 0.03 \\
\hline $\mathrm{Cr}$ & 16.71 & 0.14 & $\mathrm{Cr}$ & 17.31 & 0.14 & $\mathrm{Ca}$ & 0.83 & 0.03 & $\mathrm{Cr}$ & 9.56 & 0.09 \\
\hline $\mathrm{Fe}$ & 62.11 & 0.35 & $\mathrm{Fe}$ & 64.66 & 0.34 & $\mathrm{Ti}$ & 0.00 & 0.03 & $\mathrm{Fe}$ & 35.09 & 0.22 \\
\hline $\mathrm{Ni}$ & 6.80 & 0.12 & $\mathrm{Ni}$ & 6.99 & 0.13 & V & 0.07 & 0.03 & $\mathrm{Ni}$ & 3.66 & 0.08 \\
\hline $\mathrm{Zn}$ & 0.36 & 0.09 & Total & 100.00 & & $\mathrm{Cr}$ & 6.77 & 0.09 & Total & 100.00 & \\
\hline \multirow[t]{4}{*}{ Total } & 100.00 & & & & & $\mathrm{Fe}$ & 21.57 & 0.20 & & & \\
\hline & & & & & & $\mathrm{Ni}$ & 4.58 & 0.09 & & & \\
\hline & & & & & & $\mathrm{Zn}$ & 2.33 & 0.09 & & & \\
\hline & & & & & & Total & 100.00 & & & & \\
\hline
\end{tabular}

\section{Discussion}

From the wear data in Figure 1, Figure 3, Figure 5, and Figure 7, it can be observed that all the bearing materials show increased wear rates in an aqueous environment compared to dry operating conditions. $\mathrm{n}$ to interfere with the transfer film formation of self-lubricating bearing materials $[3,4]$. When SustainaLube is used, the wear rates are too small to be determined within the test time of $10 \mathrm{~h}$ for all bearing materials except Thordon Thorplas. However, the wear of Thordon Thorplas is substantially reduced compared to dry and aqueous lubricating conditions. Thus, the polyhydric alcohol-based EAL shows beneficial effects in terms of reduced friction and wear for all the self-lubricated bearing materials tested in this work. A mechanism called selective transfer has been discussed in literature for tribological systems containing bronze and a type of polyhydric alcohol called glycerol [15,16]. This mechanism is associated with the dissolution of certain alloying elements, e.g., zinc, into the 
glycerol system and the transfer film is normally enriched in copper [16]. In this study, a decrease of zinc at the counter-surfaces could support the theory, however, no evidence of copper transfer can be found. Selective transfer is also associated with the decomposition of glycerol into low molecular weight products which can polymerize and form a gel-like substance. Fine metal fragments and the gel-like substance then agglomerates into particles. These particles are believed to participate in the transfer film formation, resulting in a heterogeneous transfer film with organic material [16]. EDS analysis performed in this study also shows that parts of the wear track are rich in organic components when SustainaLube is used, especially for the bronze-based deva.bm but also for the polymer composite Thordon Thorplas. Surface topography measurements and SEM micrographs of the stainless steel counter-surfaces show that more of the Thordon Thorplas polymer material is transferred in water lubrication than when SustainaLube is used. It seems as if SustainaLube interferes with the self-lubricating properties of the polymer, yet a very favourable friction and wear situation still occurs.

\section{Materials and Methods}

\subsection{Friction and Wear Tests}

The experiments were performed using a Cameron-Plint machine, Plint-TE77 (Cameron-Plint Tribology Ltd., Wokingham, England). A $4 \times 4 \times 4 \mathrm{~mm}^{3}$ polymer test sample was placed inside a pin holder and rubbed against a stainless steel (SS2333) counter-surface. All tests were performed at ambient temperatures and each test was repeated two times. A displacement sensor was used to continuously measure the wear during the tests. The test time was $10 \mathrm{~h}$ for all of the tests performed. The test conditions can be seen in Table 6 .

Table 6. Test conditions: Cameron-Plint machine.

\begin{tabular}{ccc}
\hline Parameter & Unit & Value \\
\hline Frequency & $\mathrm{Hz}$ & 2 \\
Stroke length & $\mathrm{mm}$ & 5 \\
Polymer test sample dimensions & $\mathrm{mm}^{3}$ & $4 \times 4 \times 4$ \\
Load & $\mathrm{N}$ & 320 \\
Surface pressure & $\mathrm{MPa}$ & 20 \\
Temperature & & Ambient \\
\hline
\end{tabular}

Four commercially-available bearing materials for hydropower applications were investigated in this work (see Table 7). The bearing materials were: sintered bronze, two thermoset composite materials, and one thermoplastic polymer material. Three different types of lubricating conditions were used: dry, aqueous, and lubricated with SustainaLube, which is a polyhydric alcohol-based environmentally-acceptable lubricant (EAL).

Table 7. Bearing materials used in this work.

\begin{tabular}{cc}
\hline Bearing Material Trade Name & Description \\
\hline deva.bm & Sintered bronze sliding layer with solid lubricant. \\
deva.tex & PTFE sliding layer on glass-fibre reinforced carrying layer. \\
Orkot TXM Marine & Reinforced medium weave polymer material with PTFE. \\
Thordon Thorplas & Homogeneous thermoplastic polymer material. \\
\hline
\end{tabular}

\subsection{Surface Analysis}

Based on the results from the tribological experiments two bearing materials, the thermoplastic Thordon Thorplas and bronze-based deva.bm, were selected for further surface analysis to investigate the origin of the very different friction and wear response of water compared to the polyhydric 
alcohol-based SustainaLube. The same operating conditions as for the friction and wear tests were used (see Table 6). The bearing material and lubricant combinations tested can be found in Table 8 .

Surface topography measurements were performed using a Zygo (NewView 7300 3D, Middlefield, CT, USA) optical profilometer. A scanning electron microscope (SEM) equipped with an energy-dispersive X-ray spectrometer (JEOL JSM-IT300LV, Peabody, MA, USA) was used to further analyse the stainless steel counter-surfaces after the tests.

Table 8. Selected bearing material and lubricant combinations for the surface analysis.

\begin{tabular}{ccc}
\hline Bearing Material & Lubricant & Time \\
\hline Thordon Thorplas & Water & $8 \mathrm{~h}$ \\
Thordon Thorplas & SustainaLube & $8 \mathrm{~h}$ \\
deva.bm & Water & $0.5 \mathrm{~h}$ \\
deva.bm & SustainaLube & $0.5 \mathrm{~h}$ \\
deva.bm & SustainaLube & $8 \mathrm{~h}$ \\
\hline
\end{tabular}

\section{Conclusions}

In this work, the friction and anti-wear properties of a polyhydric alcohol-based EAL, used together with conventional self-lubricating bearing materials in a conformal contact under boundary lubricating conditions, have been studied. Results show that:

- The polyhydric alcohol-based EAL shows much lower friction coefficients together with all bearing materials compared to the friction under aqueous and dry operating conditions.

- Wear is significantly reduced to very low levels for all bearing materials with the polyhydric alcohol-based EAL compared to the wear under in aqueous and dry operating conditions.

- Material transfer to the counter-surface is limited when the polyhydric alcohol based EAL is used.

- A run-in period can be observed in the tribological experiments for the polyhydric alcohol-based EAL. The drop in friction and wear is accompanied by changes in both surface roughness and changes in elemental composition of the surface.

Acknowledgments: The research presented in this work was carried out as a part of "Swedish Hydropower Centre-SVC". SVC has been established by the Swedish Energy Agency, Energiforsk, and Svenska Kraftnät together with Luleå University of Technology, KTH Royal Institute of Technology, Chalmers University of Technology, and Uppsala University. Participating companies and industry associations are: Alstom Hydro Sweden, Andritz Hydro, E.ON Vattenkraft Sverige, Falu Energi and Vatten, Fortum Generation, Holmen Energi, Jämtkraft, Jönköping Energi, Karlstads Energi, Mälarenergi, Norconsult, Rainpower, Skellefteå Kraft, Sollefteåforsens, Statkraft Sverige, Sweco Energuide, Sweco Infrastructure, SveMin, Umeå Energi, Vattenfall Research and Development, Vattenfall Vattenkraft, VG Power, WSP Samhällsbyggnad, and ÅF Industry.

Author Contributions: Kim Berglund and Yijun Shi conceived and designed the experiments; Yijun Shi performed the experiments; Kim Berglund and Yijun Shi analysed the data; Yijun Shi developed and contributed with the polyhydric alcohol-based EAL; and Kim Berglund wrote the paper.

Conflicts of Interest: The authors declare no conflict of interest.

\section{References}

1. Lindsjo, H. Oil-free hubs spare hydro's blushes. Int. Water Power Dam Constr. 1999, 51, 19-21.

2. Omrani, E.; Dorri Moghadam, A.; Menezes, L.P.; Rohatgi, K.P. New Emerging Self-lubricating Metal Matrix Composites for Tribological Applications. In Ecotribology: Research Developments; Springer: Cham, Switzerland, 2016.

3. Mens, J.; De Gee, A. Friction and wear behaviour of 18 polymers in contact with steel in environments of air and water. Wear 1991, 149, 255-268. [CrossRef]

4. Lancaster, J. Lubrication of carbon fibre-reinforced polymers part I-Water and aqueous solutions. Wear 1972, 20, 315-333. [CrossRef] 
5. Meng, H.; Sui, G.X.; Xie, G.Y.; Yang, R. Friction and wear behavior of carbon nanotubes reinforced polyamide 6 composites under dry sliding and water lubricated condition. Compos. Sci. Technol. 2009, 69, 606-611. [CrossRef]

6. Bahadur, S. The development of transfer layers and their role in polymer tribology. Wear 2000, 245, 92-99. [CrossRef]

7. Jintang, G. Tribochemical effects in formation of polymer transfer film. Wear 2000, 245, 100-106. [CrossRef]

8. Clarke, C.; Allen, C. The water lubricated, sliding wear behaviour of polymeric materials against steel. Tribol. Int. 1991, 24, 109-118. [CrossRef]

9. Sulek, M.; Wasilewski, T. Tribological properties of aqueous solutions of alkyl polyglucosides. Wear 2006, 260, 193-204. [CrossRef]

10. Sulek, M.W.; Wasilewski, T.; Kurzydłowski, K.J. The Effect of Concentration on Lubricating Properties of Aqueous Solutions of Sodium Lauryl Sulfate and Ethoxylated Sodium Lauryl Sulfate. Tribol. Lett. 2010, 40, 337-345. [CrossRef]

11. Ratoi, M.; Spikes, H. Lubricating properties of aqueous surfactant solutions. Tribol. Lett. 1999, 42, 479-486. [CrossRef]

12. Matta, C.; Joly-Pottuz, L.; Bouchet, M.D.B.; Martin, J.; Kano, M.; Zhang, Q.; Goddard, W. Superlubricity and tribochemistry of polyhydric alcohols. Phys. Rev. B 2008, 78, 085436. [CrossRef]

13. Joly-Pottuz, L.; Martin, J.; Bouchet, M.D.B.; Belin, M. Anomalous low friction under boundary lubrication of steel surfaces by polyols. Tribol. Lett. 2009, 34, 21-29. [CrossRef]

14. Habchi, W.; Matta, C.; Joly-Pottuz, L.; De Barros, M.; Martin, J.; Vergne, P. Full film, boundary lubrication and tribochemistry in steel circular contacts lubricated with glycerol. Tribol. Lett. 2011, 42, 351-358. [CrossRef]

15. Assenova, E.; Kandeva, M. Self-organization and selective transfer in tribology. In Proceedings of the 8th International Conference on Tribology, Sinaia, Romania, 30 October-1 November 2014.

16. Myshkin, N.K. Friction transfer film formation in boundary lubrication. Wear 2000, 245, 116-124. [CrossRef]

(c) 2017 by the authors. Licensee MDPI, Basel, Switzerland. This article is an open access article distributed under the terms and conditions of the Creative Commons Attribution (CC BY) license (http:/ / creativecommons.org/licenses/by/4.0/). 